\title{
A VUELTAS CON LAS FALTAS. ¿QUÉ HAY DE NUEVO?
}

\author{
Rubén HerRero GimÉNEZ \\ Abogado en ejercicio \\ Dpto. de Derecho Penal \\ Universidad Complutense de Madrid \\ berrerogimenez@icam.es
}

Hace muy poco ${ }^{1}$ ha sido publicado el Proyecto de Ley Orgánica por la que se modifica la LO 10/1995, de 23 de noviembre, del Código Penal. A continuación me ocuparé de analizar algunas de las justificaciones y propuestas realizadas por el legislador para suprimir el elenco de faltas recogidas en el Libro III del Código Penal.

\section{BREVE REFERENCIA A LOS ANTECEDENTES}

Antes de nada procede hacer mención, aunque sea a vuela pluma, de las diferentes etapas que ha sufrido la regulación de las faltas en los diferentes códigos precedentes ${ }^{2}$.

A principios del siglo XIX $(1822)^{3}$ no existía regulación alguna que se ocupara de las faltas. No fue hasta veintiséis años después que se regularon

${ }^{1} 20$ de septiembre de 2013, Exposición de Motivos del Proyecto de Ley Orgánica por la que se modifica la LO 10/1995, de 23 de noviembre, del Código Penal, punto XXXII.

2 No entraremos en la reforma operada en los años 2003 ni 2010 debido a que extiende el objeto de este trabajo.

${ }^{3}$ El CP decretado por las Cortes el 8 de junio y sancionado por el rey y mandado promulgar el 9 de julio de 1822 constaba de un título preliminar, una parte primera (referente a los delitos contra la sociedad) compuesta, a su vez, por nueve títulos (entre los que se encontraban los delitos contra la Constitución y orden político de la monarquía; los delitos contra la seguridad exterior del Estado; los delitos contra la seguridad interior del Estado y contra la tranquilidad y orden público; los delitos contra la salud pública; los delitos contra la fe pública; delitos y culpas de los funcionarios públicos en el ejercicio de sus cargos; delitos contra las buenas costumbres; de los que rehúsan al Estado los servicios que le deben; los delitos y culpas de los impresores, libreros y otras personas en el abuso de la libertad de imprenta), y una parte segunda, referente a los delitos contra los particulares (que a su vez estaba integrada por tres títulos; el primero referente a los delitos contra las personas; el segundo referente a los delitos contra la honra, fama y tranquilidad de las personas, y el tercero que se ocupaba de los delitos contra la propiedad de los particulares). 
por primera vez en el Libro III (1848) ${ }^{4}$. Y así llegó la denominada clasificación tripartita ${ }^{5}$. Las faltas penales, como puede comprobarse a lo largo de nuestra historia, han estado presentes en nuestros códigos punitivos.

El legislador en la LO 3/1989, de 21 de junio ${ }^{6}$, de actualización del Código Penal, redujo el elenco de faltas (existentes en el Libro III CP) basándose en el «principio de intervención mínima» ${ }^{7}$, en la existencia

${ }^{4}$ Este Código Penal fue el primero que incorporó un libro tercero referente a las faltas. El primer libro se encargaba de recoger las disposiciones generales sobre los delitos y faltas de las personas responsables y las penas, y éste, a su vez, estaba integrado por seis títulos: el primero atendía a los delitos y faltas y circunstancias que eximían, atenuaban o gravaban la responsabilidad criminal; el segundo título se ocupaba de las personas responsables de los delitos y faltas; el tercero, de las penas; el cuarto, de la responsabilidad civil; el quinto, de las penas en que incurren los que quebrantan las sentencias y los que durante la condena delinquen de nuevo, y el sexto referente a la prescripción de las penas. Por su parte, el libro segundo albergaba los delitos y sus penas, y, por último, el libro tercero, que se ocupaba de las faltas. En el Real Decreto de 30 de junio de 1850 sigue contando con un libro III referente a las faltas (compuesto por dos títulos). Véase la Ley de 17 de junio de 1870, estructurado también en tres libros y, a su vez, compuesto su libro III por cinco títulos: el primero, respecto a las faltas de imprenta y contra el orden público; el segundo, de las faltas contra los intereses generales y régimen de las poblaciones; el tercero, de las faltas contra las personas; el cuarto, de las faltas contra la propiedad, y el quinto, disposiciones comunes a las faltas. El Real Decreto-ley de 8 de septiembre de 1928 sigue manteniendo tres libros, compuesto, a su vez, por nueve títulos: el primero compuesto por dos capítulos, correspondiendo el primero a las faltas de imprenta y otras análogas, y el segundo, a las faltas contra el orden público; el segundo, de las faltas contra los intereses generales y régimen de las poblaciones; el tercero, de las faltas contra la independencia de los funcionarios públicos; el cuarto, de las faltas contra la moralidad pública; el quinto, de las faltas contra las personas; el sexto, de las faltas contra la propiedad; el séptimo, de las faltas contra el contrato de trabajo; el octavo, de las faltas contra los menores, y el noveno, las disposiciones comunes a las faltas. La Ley de 27 de octubre de 1932 contaba también con tres libros, y el libro III contaba con cinco títulos: el primero referente a las faltas de imprenta y contra el orden público; el segundo, faltas contra los intereses generales y régimen de las poblaciones; el tercero, faltas contra las personas; el cuarto, faltas contra la propiedad, y el quinto, disposiciones comunes a las faltas. El Decreto de 23 de diciembre de 1944, ordenado conforme a los preceptos y orientaciones de la Ley de Bases de 19 de julio de 1944, formado por tres libros, y el tercero, «De las faltas», compuesto por cinco títulos: el primero, de las faltas de imprenta y contra el orden público; el segundo, de las faltas contra los intereses generales y régimen de las poblaciones; el tercero, de las faltas contra las personas; el cuarto, de las faltas contra la propiedad, y el quinto, de las disposiciones comunes a las faltas. Véase el Código Penal de 1973, Decreto 3096/1973, de 14 de septiembre, por el que se publica el Código Penal, texto refundido conforme a la Ley 44/1971, de 15 de noviembre.

5 Íñigo Segrelles de Arenaza, Compendio de Derecho penal español. Parte Especial, Madrid, Marcial Pons, 2000, pp. 1113 y ss.

${ }^{6}$ BOE de 22 de junio de 1989.

7 Así, en la LO 3/1989, de 21 de junio, y concretamente en su Preámbulo, el legislador afirma que «los delitos veniales» integran un cuerpo de infracciones penales de excesiva amplitud. Véase Manuel Ayo Fernández, Las faltas en el Código Penal y el juicio de faltas, 7. ${ }^{\text {a }}$ ed., Cizur Menor, Aranzadi Thomson Reuters, pp. 23 y ss. 
de «agolpamiento [en] los Tribunales de Justicia de muchos problemas que no [merecían] [...] el dispendio de tantos esfuerzos de los poderes públicos» ${ }^{8}$. En dicho momento, asimismo, se afirmó que dicha supresión se debía a la «falta de relevancia penal» ${ }^{9}$ y de «sentido antijurídico» ${ }^{10}$.

Llama poderosamente la atención el hecho de que ya el legislador, en dicho Preámbulo, aludía a que «la solución más simple y tajante hubiera sido la total supresión de dicho Libro», pero que «de una lectura detenida del mismo [se] pone de manifiesto que alguno de los comportamientos que sanciona debe proseguir en la esfera penal, y que incluso merece ser elevado a la condición de delito, por lo que el recurso a la derogación debe ser también usado cuidadosamente» ${ }^{11}$. Dichos criterios (adoptados en la LO 3/1989) son asumidos por el legislador en la presente reforma, suprimiendo el Libro III y rescatando ciertas faltas que eleva a la nueva categoría de delitos leves con la única justificación (como afirmaba dicho Preámbulo) de que «merece ser elevado a la condición de delito».

\section{RESPECTO A LOS CRITERIOS RECOGIDOS EN LA EXPOSICIÓN DE MOTIVOS}

El punto XXXII de la Exposición de Motivos del presente Proyecto de Reforma se ocupa de las diferentes razones que justifican tanto la creación de la nueva categoría «delitos leves» como la supresión de las faltas que no sólo producirá la eliminación del Libro III del Código Penal, sino también del resto de normas sustantivas ${ }^{12}$ y procesales ${ }^{13}$ de nuestro ordenamiento jurídico.

8 Preámbulo de la LO 3/1989, de 21 de junio.

${ }^{9}$ Ibid.

${ }^{10}$ Ibid.

${ }^{11}$ Ibid.

12 Respecto al Código Penal (LO 19/95, de 23 de noviembre), no significará únicamente la derogación de todo el libro III, sino, asimismo, la modificación de numerosos artículos que hacen referencia a las faltas. Véanse respecto al libro I los arts. $7,9,10,11,13.3 .^{\circ}, 15.2 .^{\circ}$, $27,30.1,53.1,73,120.1 .^{\circ}, 120.2 .^{\circ}, 120.3 .^{\circ}, 120.4 .^{\circ}, 120.5 .^{\circ}, 129.1 .^{\circ}, 129.2 .^{\circ}, 130.5 .^{\circ}$ y $131.2 .^{\circ}$, y respecto al libro II, arts. $173.2,177,210,515,570$ bis 1 y 570 ter $1 . c$ ).

Respecto a la Ley de Menores (LO 5/2000, de 12 de enero), deberán modificarse los arts. $1.1,18$ y $60.2,3,4$ y 5 .

Respecto a la Ley de Amnistía (Ley 46/1977, de 15 de octubre), art. I.a) y II, art. 2.a) y e), art. 4 y art. 19.2 .

Respecto a la Ley de Medidas de Protección Integral contra la Violencia de Género (LO 1/2004, de 28 de diciembre), deberán modificarse los arts. 21.4, 25, 44.1.d), 56 (respecto a la adición del apdo. 5 del art. 962 de la LECrim.), 57 (respecto a la adición del 
A continuación entramos a examinar dichas razones, que pueden ser englobadas y clasificadas en tres apartados: un primer apartado, en el que se pueden agrupar las razones dogmáticas; un segundo, en el que se establecen los «principios», y un tercero, en el que podemos reunir las razones de tipo «procesal»:

a) Razones de índole dogmática. El legislador afirma que:

- «El Derecho penal se encuentra reservado para los conflictos de especial gravedad».

- «En nuestro Derecho no existe una diferencia cualitativa entre delitos y faltas, las diferencias son puramente formales».

- «La condición de delito leve se atribuye cuando la pena prevista por su extensión pueda considerarse como leve y como menos grave».

— «El plazo de prescripción de estas infracciones se establece en un año».

— «No toda actuación culposa de la que se deriva un resultado dañoso debe dar lugar a responsabilidad penal».

b) Principios inspiradores que motivan dicha reforma:

— «Respuesta eficaz y ágil de los conflictos».

- «Derecho Penal reservado para los conflictos de especial gravedad».

- «Principio de intervención mínima y la consideración del sistema punitivo como última ratio».

- «Se introduce el criterio de oportunidad que permitirá a los jueces, a petición del Ministerio Fiscal, valorada la escasa entidad del hecho y la falta de interés público, sobreseer estos procedimientos, y así respetar el principio de intervención mínima».

c) Consecuencias en el plano procedimental:

art. 49 bis en su apdo. 3. ${ }^{\circ}$ de la LEC), 58 [respecto el art. 14.5.d) de la LECrim.], 59 (respecto al art. 15 bis de la LECrim.), 60 (respecto al art. 17 bis de la LECrim.), 71.a) (respecto a la sustitución de los párrafos segundo y tercero del apdo. 1 del art. 18 de la Ley 50/1981, de 30 de diciembre, reguladora del Estatuto Orgánico del Ministerio Fiscal).

${ }^{13}$ Véase, a modo de ejemplo, el Real Decreto de 14 de septiembre de 1882, aprobatorio de la Ley de Enjuiciamiento Criminal: no se suprimirá el libro VI respecto al «procedimiento para el juicio sobre faltas» por expreso mandato del legislador, debido a que los Juzgados de Instrucción y los Juzgados de Violencia de género asumirán la competencia para el fallo y conocimiento de los delitos leves [arts. 14.1, 3 y $5 . d$ ), 15 bis, 17 bis, 72, 75, 104, 105, 122, $142.5,203,212,247,495,544$ ter $4,742,781,855]$. 
- «Los delitos leves se establecen con un amplio margen de apreciación para que el juez o Tribunal pueda valorar la gravedad de la conducta».

— «La reforma se completa con una remisión de la regulación del juicio de faltas que contiene la LECrim. que continuará siendo aplicada a los delitos leves».

- «Los delitos leves que sustituyen a las faltas penales de más frecuente comisión seguirán sustanciándose conforme al procedimiento previsto para el juicio de faltas en el Libro VI de la vigente LECrim., manteniendo los Juzgados de Instrucción y los Juzgados de Violencia de género de competencia para el conocimiento y fallo de estos delitos».

Pues bien, una vez ordenadas las justificaciones esbozadas por el legislador, merece hacer las siguientes consideraciones:

Primera. ¿Está aplicando realmente el legislador el principio de intervención minima del Derecho Penal?

No parece que el legislador (en este Proyecto de Reforma del Código Penal) esté haciendo uso (mediante la derogación de las faltas) de uno de los mayores principios del Derecho Penal, como lo es el principio de intervención mínima.

Si, como afirma el legislador, «el Derecho penal se encuentra reservado para los conflictos de especial gravedad», y obra movido por «el principio de intervención mínima o última ratio», ¿por qué en lugar de suprimir determinadas conductas (y eliminarlas definitivamente del Código Penal) se opta por elevarlas a la categoría de delito ${ }^{14}$ ?

El hecho de que determinados comportamientos no se encuentren regulados como falta (ni tampoco como ilícito administrativo) faculta al Tribunal para que dichas conductas se enjuicien como delitos leves y no por las derogadas faltas (por no tener el intérprete capacidad para aplicar otro precepto), quebrándose el principio enunciado por el legislador de «última ratio» del Derecho penal.

Parece que lo que el legislador está proponiendo con esta reforma se asemeja más a la aplicación del principio de proporcionalidad que al principio de intervención mínima ${ }^{15}$ del Derecho penal. Si se suprimiesen todas

\footnotetext{
${ }^{14}$ Véanse las diferentes faltas de abandono de los arts. 618.1 y 619 ó 617.1, lesiones, amenazas y coacciones de carácter leve.

${ }^{15}$ Vid. Joaquín Cuello Contreras, El Derecho penal español. Parte general. Nocio-
} 
las faltas, realmente, podría pensarse que se está aplicando el principio de intervención mínima, pero al incorporar (como delitos leves) determinados comportamientos y no dejando posibilidad al juez ${ }^{16}$ a que dicho comportamiento pueda ser instruido ${ }^{17}$ por otros ordenamientos (como, por ejemplo, el administrativo sancionador) deja sin contenido dicha justificación.

El principio de intervención mínima es un mandato (al que se encuentra sometido el legislador) por el que, de los diferentes comportamientos contrarios a Derecho, éste debe escoger «aquellos más intolerables y más lesivos para los bienes jurídicos más importantes» ${ }^{18}$, «tipificando [aquéllos] verdaderamente lesivos o peligrosos» ${ }^{19}$.

La proporcionalidad, por su parte, es una «exigencia exclusivamente originada por la consideración del Estado democrático en cuanto límite impuesto a su ejercicio del ius puniendi» ${ }^{20}$. Dicho principio hace referencia

nes introductorias. Teoría del delito, Madrid, Dykinson, 2002, pp. 68 y ss. Principio básico del Derecho penal mediante el cual la potestad punitiva del Estado queda supeditada para aquellos comportamientos de «importancia o trascendencia» suficiente que tan sólo puedan ser «tratados» con la pena.

Véase STC 55/1996, de 28 de marzo (BOE, núm. 102, pp. 48 y ss.), cuestiones de constitucionalidad 961/1994, 115/1995 y 2736/1995 (acumuladas), fundamento de Derecho séptimo: «En el elemento esencial del principio de proporcionalidad penal», pues para que «la pretendida desproporción tenga alcance constitucional es preciso que implique "un sacrificio innecesario de 105 derechos que la Constitución garantiza” (SSTC 66/1985 y 19/1988)».

${ }_{16}$ Véase STC 136/1999, de 20 de julio, recurso de amparo 5459/1997 (avocado al Pleno) (BOE, núm. 197, suplemento, miércoles 18 de agosto de 1999, FJ 21, p. 45): «Es la ley, en una primera instancia, la que debe garantizar que el sacrificio de los derechos de los ciudadanos sea el mínimo imprescindible y que los límites y restricciones de los mismos sean proporcionados. Por ello, en tanto una condena penal pueda ser razonablemente entendida como aplicación de la ley, la eventual lesión que esa aplicación pueda producir en los referidos derechos será imputable al legislador y no al juez».

${ }_{17}$ Dándose la posibilidad al juez para que lo archive (por aplicación del principio de intervención mínima) y derivándose el asunto a otra jurisdicción.

${ }_{18}$ Véase Francisco Muñoz Conde, Teoría General del Delito, Bogotá (Colombia), Temis, 1984, pp. 39 y 40.

${ }_{19}$ Ibid., pp. 48 y 49. Pero, tal y como afirma este autor, «esto es un desideratum que no siempre se cumple. De ahí la necesidad de tener presente siempre una actitud crítica tanto frente a los bienes jurídicos protegidos como a la forma de protegerlos penalmente [...] el derecho penal sólo debe intervenir en casos de ataques graves a bienes jurídicos muy importantes y en la media en que sean insuficientes para sancionarlos otros medios jurídicos menos radicales» (p. 69).

${ }^{20}$ Véase Octavio DE Toledo y Ubieto, Sobre el concepto del Derecho Penal, Madrid, Universidad de Derecho, Facultad de Derecho, Sección de Publicaciones, 1981, p. 367. Véase también Isabel Perello DomeneCh, «El principio de proporcionalidad y la jurisprudencia constitucional», Dialnet, núm. 28, 1997, pp. 69-75. Si atendemos a la «formulación europea del principio de proporcionalidad en sentido amplio», se debe hacer mención a los diferentes «elementos o subprincipios» que lo componen: el de la «utilidad o adecuación», juicio por el que debe ser idónea la medida en relación con el fin, o, en otras palabras, «que al menos faci- 
a la relación entre «la gravedad del injusto y la de la pena» ${ }^{21}$. Con la derogación de las faltas (y consecuente creación de los delitos leves) se crea una respuesta más agravada respecto al mismo comportamiento. Si se hubiesen mantenido las faltas y se utilizase el principio de oportunidad ${ }^{22}$ (tal y como alude el legislador), podría (como posibilidad) acudir a enjuiciarse el comportamiento como unas faltas y no como un delito ${ }^{23}$; no obstante, con esta pretendida reforma, el principio de oportunidad queda sometido una intervención aumentada a la medida de la pena de un delito y no al de una falta.

\section{Segunda. ¿Qué diferencias existen entre los delitos y las faltas?}

Debemos clasificar estas diferencias en dogmáticas y procesales. En cuanto a las primeras, el legislador afirma que en nuestro Derecho no

lite o tienda a la consecución del objetivo propuesto»; el de la «necesidad o indispensabilidad», donde «la medida debe ser necesaria, o la más moderada entre todos los medios útiles [...] la acción se legitima (en tanto que) no hay otra más suave o moderada a tal propósito», y el de «proporcionalidad strictu sensu», esto es, proporcionada, «ponderada o equilibrarse por derivarse de ella más beneficios y ventajas que perjuicios sobre otros bienes o valores en conflictos, en particular sobre los derechos y libertades» (p. 70).

Véase Santiago Mir Puig, Introducción a las bases del Derecho Penal. Concepto y método, Barcelona, Bosch, 1976. Se interpreta el principio de proporcionalidad como uno de los límites del poder punitivo, además de la «exclusiva protección de bienes jurídicos y el principio de culpabilidad» (pp. 151 y ss.); se trata de «un límite del ius puniendi que impone el Estado democrático en el momento legislativo de la conminación típica y se expresa a través del principio de proporcionalidad» (pp. 158 y ss.).

${ }^{21}$ Véase Antonio García-Pablos de Molina, Introducción al Derecho Penal, 4. ${ }^{a}$ ed., Madrid, Ramón Areces, pp. 580 y ss. Ver más ampliamente respecto al concepto de proporcionalidad en toda su extensión.

${ }^{22}$ Véase STC 136/1999, de 20 de julio, recurso de amparo 5459/1997 (avocado al Pleno) (BOE, núm. 197, suplemento, miércoles 18 de agosto de 1999, FJ 23, p. 46): «La relación de proporción que deba guardar un comportamiento penalmente típico con la sanción que se le asigna será el fruto de un complejo juicio de oportunidad» que no supone una mera ejecución o aplicación de la Constitución, y para el que «ha de atender no sólo al fin esencial y directo de protección al que responde la norma, sino también a otros fines legítimos que pueda perseguir con la pena y a las diversas formas en que la misma opera y que podrían catalogarse como sus funciones o fines inmediatos a las diversas formas en que la conminación abstracta de la pena y su aplicación influyen en el comportamiento de los destinatarios de la norma - intimidación, eliminación de la venganza privada, consolidación de las convicciones éticas generales, refuerzo del sentimiento de fidelidad al ordenamiento, resocialización, etc.- y que se clasifican doctrinalmente bajo las denominaciones de prevención general y de prevención especial».

${ }^{23}$ Véase M. ${ }^{a}$ Isabel Martínez GonZÁlez y Elena Núñez Castaño, Nociones fundamentales del Derecho Penal. Parte General, 2. ${ }^{a}$ ed., Madrid, Tecnos, septiembre de 2010, pp. 70 y ss. Si persistieran las faltas se podría aplicar el principio de intervención mínima del Derecho penal («en su dimensión interna [...] que obliga a prescindir de una determinada sanción penal si los efectos preventivos se pueden alcanzar mediante otra sanción penal menos gravosa $[. .$.$] siendo una de sus manifestaciones el principio de proporcionalidad»).$ 
existe una diferencia cualitativa entre delitos y faltas, y que dichas diferencias son puramente formales. Al respecto hay que decir que un sector de la doctrina ${ }^{24}$ coincide en que parte de las diferencias entre delitos y faltas son cuantitativas, por cuanto «la diferencia viene establecida por el mayor o menor contenido de injusto» ${ }^{25}$. En este sentido hay que decir que relativizar (y, con ello, justificar el legislador en este Proyecto de Reforma de LO) que la única diferencia existente entre un delito y una falta es «puramente formal» («por el carácter que le da la Ley») o «cuantitativa» («en atención al tipo de pena») supone dejar al margen que el sustrato o ratio por el que se acude a tal clasificación (ya sea formal o cuantitativa) se basa (a su vez) en el tipo de bien jurídico de que se trate o la intensidad en que se lesione o se ponga en peligro el/los bien/ es jurídico/s.

A lo largo de la historia, la doctrina ha intentado encontrar las diferencias que logren distinguir, desde el punto de vista cualitativo, el delito de la falta. Desde las teorías «sobre el diverso modo de ser de la ofensa» ${ }^{26}$, pasando por considerar, como criterio diferenciador, «la dirección de la

${ }^{24}$ Véase Francisco Muñoz Conde y Mercedes García Arán, Derecho Penal. Parte General, 8. ${ }^{a}$ ed., Valencia, Tirant lo Blanch, 2010, pp. 205 y ss.: «Es, pues, una cuestión de política legislativa el que un hecho se considere como delito grave o menos grave, o como falta $[. .$.$] distinción puramente cuantitativa [. .$.$] la distinción terminológica se hace exclu-$ sivamente en función de la gravedad de la pena que tienen prevista. El delito está castigado con pena grave o menos grave, la falta con pena leve. Esta distinción es completada a su vez en el art. 13 del Código Penal, que clasifica los delitos en delitos graves y delitos menos graves, según se trate de delitos castigados con pena grave o con pena menos grave, respectivamente $[. .$.$] la distinción depende del marco penal que abstractamente se asigne a la$ infracción en cuestión en el correspondiente tipo penal».

En el mismo sentido, véase Joaquín Cuello Contreras, El Derecho penal español. Parte General. Nociones introductorias. Teoría del delito, Madrid, Dykinson, 2002, pp. 606 y ss.

25 Íñigo Segrelles de Arenaza, Compendio de Derecho penal español. Parte Especial, op. cit., pp. 1119 y ss. Según este autor: «Estamos hablando de tipos similares, que mantienen una singularización cuantitativa, generalmente fundada en una mayor o menor lesión del bien jurídico protegido». Véase exhaustiva crónica legislativa expuesta por este autor.

Cfr. Antonio García-Pablos de Molina, Introducción al Derecho Penal, 4. ${ }^{a}$ ed., Madrid, Ramón Areces, 2006, p. 582: «El mandato de la proporcionalidad implica un juicio lógico o ponderación que compara, valorativamente, la gravedad del hecho antijurídico y la gravedad de la pena, la entidad del injusto y la del castigo del mismo».

Véase referencia crónica legislativa por Luis RodRíguez Ramos, Compendio de Derecho Penal. Parte General, 3. ${ }^{a}$ ed., Madrid, Trivium, 1986, pp. 141 y ss.

Véase codificación penal española por Juan Del Rosal, Derecho Penal español, 3. . ed., Madrid, 1960, pp. 91 y ss.

${ }_{26}$ Teorías que se basan en la «diversidad del elemento subjetivo, considerando delitos las infracciones dolosas y faltas las infracciones culposas y aquellas otras que conciben como delito las infracciones que producen una auténtica lesión del bien jurídico y como contravenciones las que originan solamente un peligro para dicho bien». Véase Juan CóRDOBA 
ofensa» ${ }^{27}$. Por su parte, la distinción cualitativa de delito y falta, a tenor de nuestro Código Penal, es una simple propuesta de lege ferenda ${ }^{28}$.

Respecto a las diferencias procesales entre las «futuras derogadas faltas y los novedosos delitos leves» se pueden apreciar las siguientes: prime$\mathrm{ra}$, «en el aspecto sustantivo, las faltas no se castigan en grado de tentativa (art. 15.2 CP); segunda, el juez goza de libertad para determinar la pena en el caso de una pluralidad de faltas (art. $638 \mathrm{CP}){ }^{29}$; tercera, las faltas prescriben a los seis meses ${ }^{30}$ y las actuales penas leves lo harán al transcurso de un año ${ }^{31}$; y, cuarta, el procedimiento de las faltas (arts. 962 y ss. LECrim.) carece de fase de instrucción (a diferencia de los delitos menos leves y los graves), sin perjuicio de otros aspectos referentes a la competencia orgánica (art. 14 LOPJ), «por cuanto las faltas son competencia de los juzgados de paz y los de instrucción, los delitos menos graves de los juzgados de lo penal y los delitos graves de las Audiencias Provinciales» ${ }^{32}$.

Otra consecuencia que puede apreciarse con la supresión del Libro III del Código Penal es que, al convertirse ciertos comportamientos en delitos leves, éstos generarán (como habitualmente comprobamos en la práctica forense) antecedentes penales al particular ${ }^{33}$; no obstante, por expresa mención del legislador, «no se apreciará a efectos de agravante de

Roda y Gonzalo Rodríguez Mourullo, Comentarios al Código Penal, t. I, Arts. 1-22, Barcelona, Ariel, 1972, pp. 196 y ss.

${ }^{27}$ En esta clasificación se aglutinan diversos criterios: a) de origen romano: «los delitos ofenden derechos innatos, naturales, originarios [...] las faltas lesionan derechos derivados, adquiridos en la organización jurídica y social»; $b$ ) «los delitos lesionan la seguridad pública o privada [...] y las leyes que las protegen como derechos naturales [...] las faltas ofenden la prosperidad pública [...] y las leyes que la protegen (Beccaria, Carrara)»; $c$ ) «los delitos ofenden derechos naturales, las faltas infringen una norma legal y el Derecho subjetivo del Estado que de ella deriva (Feuerbach)»; d) «los delitos lesionan o amenazan un bien jurídico o un derecho subjetivo, las faltas no lesionan ni amenazan bien jurídico o derecho subjetivo alguno [...] son una simple desobediencia a una norma y una pura violación del Derecho del Estado a la obediencia (Binding)». Véase más ampliamente, Juan CóRDOBA RodA y Gonzalo RodRíguez Mourullo, Comentarios al Código Penal, op. cit., pp. 196 y ss.

${ }^{28}$ Ibid., p. 197.

${ }^{29}$ Joaquín Cuello Contreras, El Derecho penal español. Parte General. Nociones introductorias. Teoría del delito, op. cit., pp. 606 y ss.

${ }^{30}$ Art. 131, apdo. 2.

${ }^{31}$ Por mandato expreso del legislador, en la Exposición de Motivos del Proyecto de Reforma del Código Penal se establece que: «el plazo de prescripción de estas infracciones se establece en un año».

${ }^{32}$ Para ver cronológicamente la regulación procesal al respecto, Íñigo SEgRELLES DE Arenaza, Compendio de Derecho penal español. Parte Especial, op. cit., pp. 1114 y ss.

33 Sin perjuicio de lo proclamado en el art. 136 del Código Penal (segundo párrafo y segundo inciso): «Haber transcurrido, sin delinquir de nuevo el culpable, los siguientes plazos $[\ldots]$ seis meses para las penas leves». 
reincidencia». Además, en el enjuiciamiento de faltas (en función de lo establecido en el art. 967 LECrim.), no es obligatorio encontrarse asistido por abogado, no siendo así en el enjuiciamiento de los delitos, donde la asistencia letrada ${ }^{34}$ es preceptiva; asimismo, es necesaria la asistencia y representación procesal (procurador) desde la apertura del juicio oral. Con ello se ocasiona otra desagradable consecuencia para el ciudadano-justiciable, como es el hecho de que, en virtud de los arts. 239 y ss. LECrim. ${ }^{35}$, puedan ser condenados a las costas del procedimiento ${ }^{36}$. No obstante, queda al margen (en aras a cubrir los posibles perjuicios) del ámbito de aplicación de la reciente Ley de Tasas ${ }^{37}$ por expresa mención del legisla-

34 Desde la simple detención e imputación [art. 520.2.c)], a cualesquiera otras diligencias que requieran de la presencia del mismo (como, por ejemplo, los recursos de cualquier índole, escritos de alegaciones, impugnación de escritos, vistas, declaraciones de testigos, etc.)

${ }^{35}$ Libro I, «Disposiciones generales», título XI, «De las costas procesales».

${ }^{36}$ Cuestión controvertida habida cuenta de lo establecido en el art. 123 CP y lo recogido en la LECrim. Respecto a lo recogido en la LECrim., en el seno del título XI tan sólo se expresa, en el art. 239: «En los autos o sentencias que pongan término a la causa o a cualquiera de los incidentes deberá resolverse sobre el pago de las costas procesales», no diferenciándose si las resoluciones emitidas en los juicios de faltas, es decir, las emitidas por los Juzgados de Instrucción (en Primera Instancia y, ulteriormente, por la Audiencia Provincial en apelación), son también susceptibles de su condena en costas, en el caso en que la parte vencedora solicite a S.S. ${ }^{a}$ que se pronuncie en su resolución acerca de si, en el comportamiento del querellante/denunciante o del querellado/denunciado, ha apreciado obrar con temeridad o mala fe, y así, en un procedimiento de faltas obtener el pago de honorarios devengados por los abogados y peritos, indemnizaciones correspondientes a los testigos que las hubieren reclamado y demás derechos que establece el art. 241 de la misma ley. Por su parte, la norma sustantiva en el art. 123 CP establece que «las costas procesales se entienden impuestas por la ley a los criminalmente responsables de todo delito o falta».

Véase José Miguel Guillén SoRIA, «Casos en que procede la imposición del pago de costas en la condena por faltas penales. Análisis de un problema práctico poco estudiado», Noticias Jurídicas, noviembre de 1999 [http://noticias.juridicas.com/articulos/65Derecho por 10020Procesal por 10020Penal/199911-not19_13.html (revisado con fecha 10 de octubre de 2013)]. Asimismo se recomienda (por este autor) la lectura de la Sentencia del Tribunal Supremo, Sala 2. ${ }^{a}$, de 9 de marzo de 1991, ponente Sr. Carrero Ramos, FD $1 .^{\circ}:$ «El único motivo del recurso interpuesto por la acusación particular se ha formalizado bajo el núm. 1. ${ }^{\circ}$ del art. 849 de la Ley de Enjuiciamiento Criminal, alegando infracción por interpretación errónea en los arts. 109, 110 y 111.3 del Código Penal. Se impugna el fallo de la sentencia de instancia en cuanto a su pronunciamiento sobre la condena en costas al inculpado, de las que se han excluido las correspondientes a la parte de la acusadora privada [...] prescinde el recurrente de un factor importante a estos efectos y es que el fallo de la sentencia absolvió al acusado del delito por el que se había procedido y sólo ha sido condenado por falta. En tales casos, la condena en costas es de las correspondientes al juicio de faltas (entre otras, Sentencias de 21 de noviembre de 1968 y 7 de marzo de 1988)».

${ }_{37}$ Ley 10/2012, de 20 de noviembre, por la que se regulan determinadas tasas en el ámbito de la Administración de Justicia y del Instituto Nacional de Toxicología y Ciencias Forenses. 
dor $^{38}$. Como podemos comprobar, las consecuencias de dicha modificación sustantiva poseen efectos en el plano procesal.

Tercero. ¿Es la supresión de las faltas una respuesta eficaz para reducir la elevada litigiosidad y agilizar la resolución de conflictos que tienen lugar en nuestros juzgados y tribunales?

En la Exposición de Motivos se afirma que la supresión del Libro III es una «respuesta eficaz y ágil de los conflictos». Difícilmente el legislador podrá descongestionar la Administración de Justicia por tamaña reforma, por cuanto la sustanciación de las faltas, en cuanto al tiempo y al esfuerzo se refiere (como bien se sabe), suele ser inmensamente inferior a la de los procedimientos abreviados y, ya no digamos, en los procedimientos ordinarios o los del jurado.

Los procedimientos de faltas (como ya hemos dicho anteriormente) carecen de instrucción y, normalmente, la enjundia o problemática a resolver en estos asuntos suele ser menor que en el resto de procedimientos.

En el Proyecto se afirma que «los delitos leves que sustituyen a las faltas penales seguirán sustanciándose [respecto al conocimiento y fallo] conforme al procedimiento [regulado] en el Libro VI LECrim.; [es decir], en los Juzgados de Instrucción y los Juzgados de Violencia de Género». De ser así, la tramitación de estos nuevos delitos leves colapsarán los juzgados debido a dos razones fundamentales; la primera es que se tendrán que instruir las oportunas diligencias ${ }^{39}$ (cosa que no ocurriría con las faltas), y la segunda es que, al no existir un comportamiento castigado con menos pena (y por ello con menos contenido de injusto), el juzgador dilatará las actuaciones más de lo que lo hacía con las faltas, teniendo la obligación ${ }^{40}$ de realizar las actuaciones pertinentes ${ }^{41}$ (con la carga de trabajo que conlleva) y, por ende, ampliándose el tiempo en las gestiones y actuaciones procesales.

${ }^{38}$ Ibid. Punto II del Preámbulo donde afirma el legislador: «Por sus características especiales de acceso a la justicia tan sólo se excepciona del ámbito de la tasa el orden penal».

${ }^{39}$ Con el tiempo que ello conlleva (práctica de diligencias, traslado de escritos, notificaciones a la representación técnica y/o procesal...) y con la eventual apertura del juicio oral (traslado a las partes para la realización de las conclusiones provisionales), eventual solicitud de diligencias de pruebas complementarias y señalamiento de fecha para la vista.

${ }^{40}$ En el caso de que el Ministerio Fiscal, según la Exposición de Motivos, estime que el valor del hecho reviste determinada entidad.

${ }^{41}$ El juez tendrá que aperturar las correspondientes diligencias, ya sea para investigar y ulteriormente archivarlas, transformarlas en el procedimiento que corresponda, o bien inhibirse a favor de la jurisdicción u órgano competente. 
Como podemos comprobar, al derogar las faltas se genera una dilatación del procedimiento que ocasiona una mayor carga de trabajo y, por consiguiente, una menor agilidad en la Administración de Justicia, justo lo contrario a lo que aspira el legislador con esta reforma. 